\title{
COMPORTAMENTO DE BEBÊS NA ROTINA DIÁRIA DA CRECHE
}

\author{
THE BEHAVIOUR OF BABIES IN THE DAILY ROUTINE \\ OF THE DAY NURSERY
}

Ligia E. Melchior 1

Zelia M. M. Biasoli-Alves 2

MELCHIOR, L.E.; BIASOLI-ALVES, Z.M.M. Comportamento de bebes na rotina diaria da creche. Rev. Bras. Cresc. Desenv. Hum., Sao Paulo, 12 (2), 2002.

\begin{abstract}
Resumo: Esse trabalho teve por objetivo verificar como e o comportamento de bebes na rotina diaria de uma creche no interior paulista. Os dados foram obtidos atraves de entrevista semiestruturada com 21 educadoras de creche, individualmente entrevistadas, sobre cada bebe de 4 a 24 meses sob seus cuidados $(n=90)$ e do diario de campo, utilizado como estrategia de coleta de dados complementar. Os dados obtidos foram analisados de fo^lma quantitativa, quantitativainterpretativa e qualitativa. Os resultados desse estudo indicam que essa amostra de bebes esta adaptada ao ambiente coletivo: apreciam o banho de sol; alimentam-se bem e passam a esperar pela papa salgada com mais tranquilidade, brincando e se locomovendo no ber ario; o sono e calmo e con'siderado numa quantidade normal; demonstram aceita ao na troca de fraldas e no banho; com o aumento da idade, apresentam maior participa $\wedge$ S ao nas atividades interativas com outros bebes. No entanto, alguns aspectos sao destacados e reconhece-se a necessidade de novas pesquisas para elucida-los.
\end{abstract}

Palavras-chave: comportamento de bebes; creche.

Cada vez mais, no Brasil, crianças de diferentes camadas sociais são levadas para creches, berçários ou hotelzinhos, desde bebês. E esse é um fenômeno mundial. Na maioria dos países industrializados, as mulheres vem, sistematicanente, fazendo parte do mercado de trabalho. Entretanto, dependendo da camada social, há diferenças marcantes na maneira de o trabalho da mulher fora do ambiente doméstico ser encarado; nos extratos economicamente dsfavorecidos ele se constitui numa necessidade e garantia de sobrevivência, enquanto que nas camadas médias ou mais elevadas ele passa a ser visto como fonte de realização e crescimento pessoal. Contudo, independentemente das discrepâncias, a colocação da criança no ambiente coletivo torna-se cada vez mais freqüente, seja porque os pais consideram que essa é uma opção mais adequada, seja porque as famílias se acham impossibilitadas de contar com parentes ou empregadas domésticas que possam assumir o cuidado de seus filhos.

A essas mudanças seguem-se outras e o berçário, a creche, a escolinha maternal vêm se transformando, deixando inclusive de serem

FAPEsP, bolsa de doutoramento, processo $n^{\circ} \wedge 1997 \wedge / 4684-7$. Esse trabalho e parte da tese da primeira autora orientada pela segunda autora denominado Desenvolvimento e comportamento de bebês (de 0 a 2 anos) na rotina diaria, segundo a visão das educadoras de ambiente coletivo, Faculdade de Filosofia Ciências e Letras de Ribeirao Preto da USP 1999.

2 Departamento de Psicologia - Universidade Estadual Paulista/UNESP - Av. Luis Edmundo Carrijo Coube s/n Bairro Vargcm Limpa, CEP 17001-970, Bauru-SP.

3 Departamento de Psicologia e Educação - Universidade de São Paulo - USP - Av. Bandeirantes n 3900 . Bairro M onte Alegre, CEP: 14040-901, Ribeirao Preto-SP. 
vistos como um mal necessário para adquirirem a conotação de facilitadores e promotores do desenvolvimento infantil. CALDWELL (1995) enfatiza que o bebê do século XXI precisa de um sistema de apoio suplementar ao da família, e que tenha qualidade, porque a ele será atribuído um papel de extrema relevância, sobretudo nas sociedades industrializadas. Nesse início de século, o panorama não mudou. À existência de um contingente grande de bebês e crianças, em algum tipo de ambiente coletivo, é mesmo uma realidade nos dias atuais, e com poucas perspectivas de que a manutenção de seus filhos em casa até a idade escolar volte a ser um padrão da maioria das famílias.

Na literatura brasileira há uma lacuna em relação à descrição de como os bebês se comportam nas situações de rotina diária no ambiente coletivo. É claro que há diferentes tipos de creche no Brasil, que a realidade de umas e de outras pode ser bem diversa, no entanto, seria preciso partir de algum ponto, até para poder dizer depois em que os bebês de outras creches se comportam de forma igual ou diferente.

Um conjunto de questões, delineadas a partir do conhecimento da rotina que a creche selecionada para essa pesquisa segue, foi estabelecida: Como os bebês reagem ao banho de sol? E na alimentação? Há choro antes? A quantidade de alimentos ingerida é considerada suficiente? Como dormem? Exigem atenção especial? Como se comportam na hora do banho e na troca de fraldas? O banho é visto como uma atividade prazerosa? O que costumam fazer nos períodos livres? Qual o humor que costumam apresentar nas diferentes situações?

A necessidade de conhecer um pouco mais de perto essa realidade é que definiu o objetivo desse estudo, que é o de descrever o comportamento de bebês de 4 a 24 meses de idade, em atividades rotineiras da creche, tais como: Chegada, Banho de Sol, Troca de Fralda, Banho, Sono, Atividade Livre, Contato com os outros bebês, Saída da Creche.

\section{MÉTODO}

\section{Caracterização da instituicão}

O Centro de Convivência infantil (CCI) de um Hospital Universitário, de uma cidade do interior de São Paulo, atende crianças de 0 a 2 anos, filhos de funcionárias do hospital, em uma pro- porção de uma educadora para cada 4, 5 crianças. $\mathrm{Na}$ época da coleta de dados contava com a seguinte equipe técnica: psicóloga, enfermeira, médica e assistente social.

\section{Sujeitos}

Colaboraram para a realização desse estudo 21 educadoras de creche, do sexo feininino, com idades variando de 21 a 57 anos, tendo entre três e dezoito anos de experiência no cuidado de bebês, na instituição em que os dados foram coletados. Vinte e quatro por cento das educadoras possuíam o primeiro grau completo, 57\% o segundo grau completo e o restante (19\%), o segundo grau incompleto. Elas cuidavam de 90 bebês de 4 a 24 meses, $49 \%$ do sexo feminino e $51 \%$ do sexo masculino, filhos de funcionárias de um hospital universitário, com nivel de escolaridade variando do primeiro grau ao superior. A profissão das mães incluía desde faxineira até médicas e administradoras.

\section{Procedimento}

Foi elaborado um roteiro para entrevista semi-estruturada, onde era solicitado que os educadores descrevessem o comportamento de cada bebê durante o período em que ele se encontrava na creche, incluindo: (a) a chegada* quando o bebê era trazido pela mãe, pai ou ambos; (b) a alimentação - mamadeira ou seio, suco, fruta, refeições, (c) o processo de higienização - troca de fraldas e banho; (d) a saída da creche* .

As educadoras foram entrevistadas na própria creche, durante o período de trabalho e, em cada entrevista, eram solicitadas a focalizar um bebê de cada vez, dentre os 4 ou 5 sob seus cuidados mais diretos. Foram realizadas 90 entrevistas com as 21 educadoras, com a duração média de 20 minutos, totalizando 30 horas de gravação em áudio.

Também foi realizado um Diário de Campo, como estratégia de dados complementar, com o objetivo de contextualizar os dados obtidos através das entrevistas, com a verificação ao vivo dos hábitos e rotinas no CCI.

\section{A análise dos dados}

As entrevistas foram transcritas na íntegra. Alguns dados foram obtidos diretamente da entrevista. Para categorizar o humor dos bebês, bem como para agrupar comportamentos específicos em categorias mais amplas, construiu-se sistemas de categorias para o relato das educadoras, que

\footnotetext{
* Esses dados estão descritas no artigo "Cornportamentos de bebês em situações de separação e reencontro com os pais, na rotina diária da crcclrc` publicado na revista Paidéia, 10^(8), em 2000. FF.C.L R.P-USP.
} 
obedeceram aos critérios de exaustividade, de exclusividade, do nível de amplitude das categorias e do nível de inferência das categorias (SIGOLO \& BIASOLI ALVES, 1998). Foi-se então computando a frequência e calculando as porcentagens, em função das variáveis sexo e idade dos bebês.

Uma análise qualitativa também foi adotada, buscando nos relatos das educadoras e no Diário de Cainpo informações que reforçassern alguns pontos e esclarecessem ou ilustrassem outros.

\section{RESULTADOS}

\section{O Banho de Sol}

No CCI, o banho de sol faz parte da rotina dos bebês de 4 a 10 meses de idade. Obteve-se o relato de 32 bebês dessa faixa etária, 50\% de cada sexo.

Cinqüenta e três por cento desses bebês tomam banho de sol no período da manhã, os demais estão dormindo nesse período (9\%) ou ausentes da creche (38\%).

As educadoras descrevem tipicamente o comportamento de cada bebê nessa situação com frases do tipo: "Ele gosta, aprecia bem, fica feliz, gosta de ficar olhando as cores das árvores, algum bichinho que voa pra lá e pra cá chamando a atenção dele, ele gosta”.

Pela descrição delas, o comportamento dos bebês é variado: há aqueles que olham objetos e plantas, as educadoras, os outros bebês, há os que pegam chocalhos, o próprio pé, enquanto outros engatinham ou ficam em pé apoiados nos carrinhos, cadeiras, pernas das educadoras. Alguns dormem durante essa atividade.

Os dados do Diário de Campo concordam com essa variedade no comportamento dos bebês, e permitem acrescentar que as educadoras interagem com eles, cantam, batem palmas, conversam entre si, e eles participam olhando na direção dos sons, dos movimentos. Há também aqueles que se mostram incomodados com a situação e choram.

\section{Alimentação}

Antes da alimentação os bebês apresentam comportamentos diversos: há os que se mantêm quietos, os que brincam e/ou se locomovem no berçário, outros choram e/ou resmungam. A Figura 1 ilustra esse tipo de dado, em função de duas grandes faixas etárias e do sexo.

A figura evidencia que o choro, resmungo ou solicitação de comida ocorre com grande freqüência para os bebês de ambos os sexos na faixa etária de 4 a 12 meses. Depois, o mais freqüente para os do sexo feminino é brincarem e/ou se locomoverem no berçário, enquanto que, para os masculinos, tanto é alta a porcentagem dos que brincam e/ou se locomovem quanto dos que protestam de alguma forma.

As observações do Diário de Campo mostraram que, no geral, os bebês mantêm-se calmos/ tranqüilos antes da papa salgada. Os de 4 a 9 meses ficam dentro do berçário, observando outros serem alimentados pelas educadoras, aguardando a sua vez, demonstrando muita tranqüilidade: observam o ambiente, emitem sons, manipulam objetos, engatinham. No entanto, na faixa etária de 10 a 12 meses, os comportamentos dos bebês divergem: a maioria chora antes de receber a alimentação.
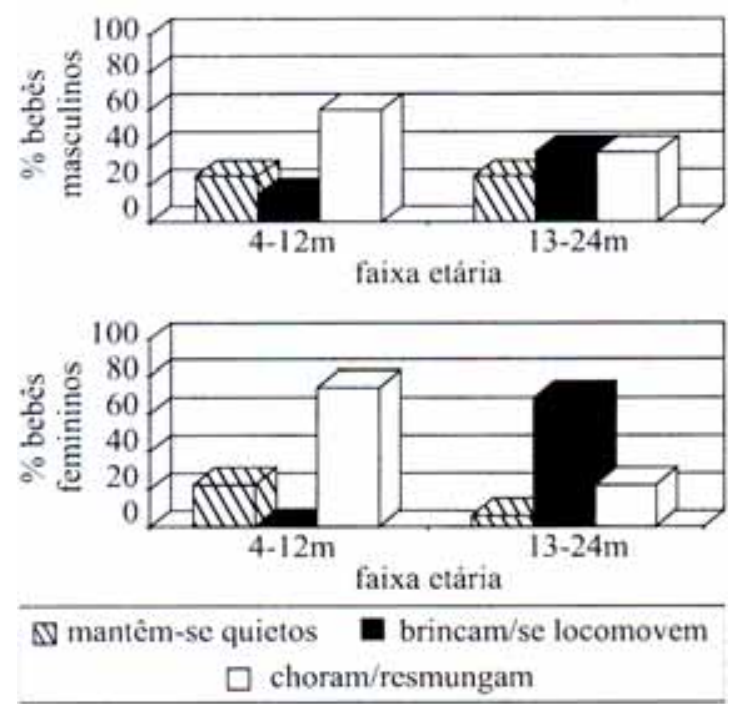

Figura 1: Proporção de ocorrência de comportamentos de bebês antes da alimentação salgada, em função do sexo e da faixa etária

\section{$O$ apetite dos bebês}

As educadoras relataram, qualificando o apetite dos bebês, se eles comiam pouco para a idade, uma quantidade normal ou exagerada. $\mathrm{O}$ apetite foi considerado normal para a maioria dos bebês de 4 a 7 e de 13 a 24 meses, de ambos os sexos. No entanto, na faixa etária de 8 a 12 meses, menos da metade dos bebês foi julgada como apresentando um apetite normal, aumentando assim os percentuais dos que comem pouco ou exageradamente, para ambos os sexos.

\section{O comportamento dos bebês após a alimentação}

$\mathrm{O}$ relato das educadoras sobre como se comportam os bebês após a alimentação, permi- 
tiu identificar quatro classes: mantêm-se quietos observando o ambiente; brincam e se locomovem pelo berçario; choram, gritam ou resmungam; dormem. Os resultados obtidas podem ser observados na Figura 2.
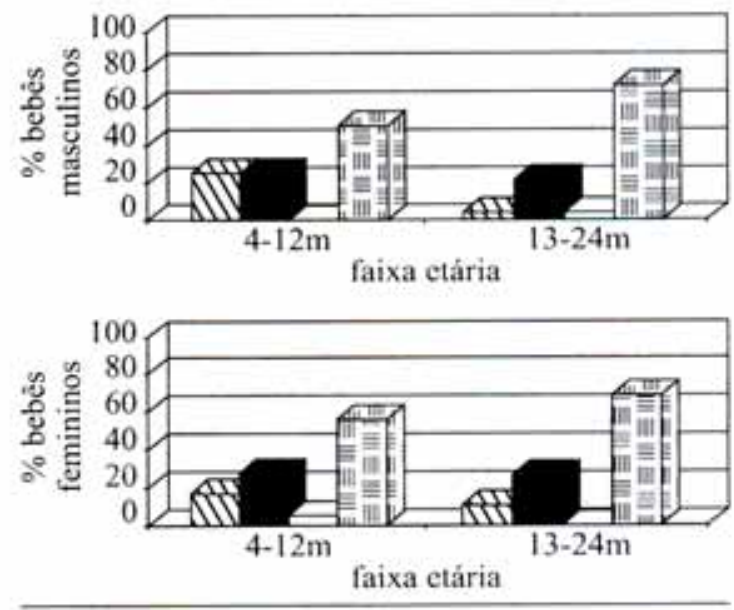

Q్ mantêm-se quietos brincam/se locomovem

choram/gritam/resmungam $\square$ dormem

Figura 2: Proporção de ocorrência de categorias de comportamentos que os bebês costumam emitir após a alimentação.

A figura mostra dados semelhantes para bebês de ambos os sexos. Pode-se observar que há aumento na proporção de bebês que dormem após a refeição salgada, de uma faixa etária para outra. A porcentagem dos que se mantêm quietos ou brincam e se locomovem decresce com o aumento da idade.

As educadoras não observam problemas em relação à alimentação de 93\% dos bebês masculinos e femininos, havendo alguma perturbação em seis, três de cada sexo (7\%), que apresentam lentidão ou rapidez exagerada ao comer, regurgitação ou vômito do alimento ingerido ou a não aceitação de alimentos sólidos.

\section{O estado de humor antes e depois da alimentação}

O estado de humor foi classificado em duas direções, em função do comportamento manitèsto dos bebês: Irritado/Intranqüilo e Calmo/Tranqüilo.

Irritado/Intranqüilo quando eles choravam, resmungavam, mostravam-se nervosos e impacientes. Houve relatos do tipo: "Ele chora, fica inquieto, impaciente, aí a gente sempre procura já oferecer o alimento. I gente sempre oferece primeiro prá quem tá mais ansioso”.

O estado de Calma/Tranqüilidade foi subdividido em dois: (a) Calmo/Tranqüilo quando os be- bês permaneciam quietos, se entretendo com alguma coisa ou observando o ambiente, independente de posições corporais: deitados, sentados, engatinhando ou andando; (b) Alegre/Feliz quando riam ou sorriam, observando o ambiente, brincando ou se locomovendo pela sala. Exemplos da fala das educadoras ilustram o estar Calmo/Tranqüilo e Alegre/Feliz, respectivamente: "Ele não fica chorando não, fica quieto, aguardando a vez dele”; “Ah, ele fica brincando, entretido, fica alegre com os brinquedinhos, ele tá sempre rindo”.

Na Figura 3 pode-se verificar o estado de humor dos bebês do sexo masculino antes e depois da alimentação salgada.

Antes da papa salgada, mais da metade dos bebes masculinos mostra-se irritada; com o aumento da idade, há diminuição neste percentual. Na faixa etária de 11 a 18 meses, mais da metade dos bebês demonstra calma e tranquilidade nessa hora. Na faixa etária seguinte, pouco mais da metade deles está calma ou alegre, mas o restante permanece irritado. Após a alimentação, o estado de calma/ tranquilidade predomina em todas as faixas etárias.

A Figura 4 mostra o percentual de bebês do sexo feminino em relação ao estado de humor que apresentam, antes e após a papa salgada.
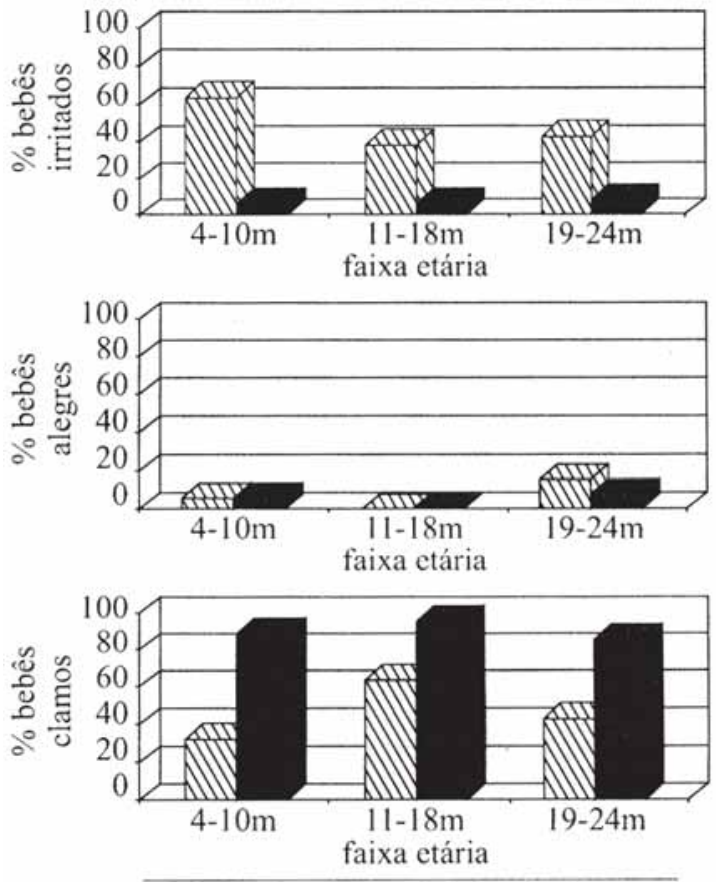

$\mathbb{\nabla}$ antes da papa $\square$ depois da papa

Figura 3. Proporção de bebês do sexo masculino que se apresentam Irritados/lntranqüilos, Calmos/Tranqüilos ou Alegres/Felizes, antes e após a papa salgada, em função da faixa etária. 

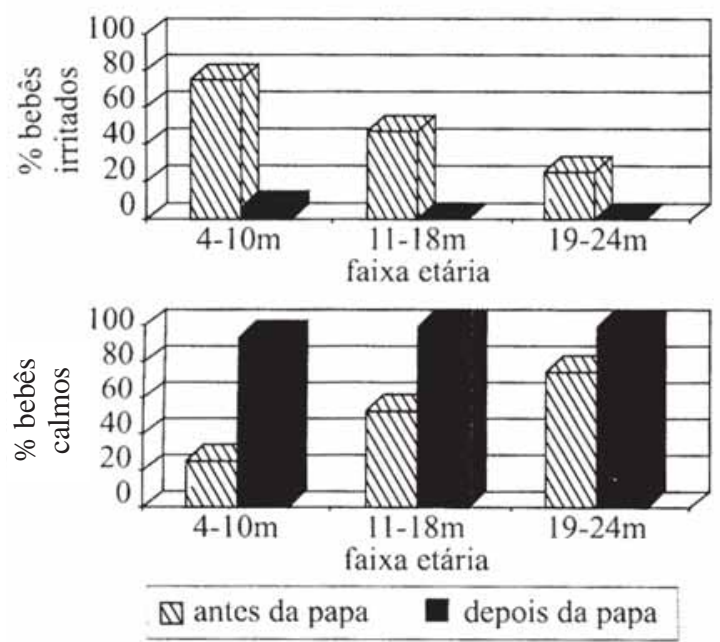

Figura 4: Proporção de bebês do sexo feminino que se apresentam Irritados/Intranqüilos ou Calmos/Tranqüilos antes e após a papa salgada, em função da faixa etária.

Pode-se verificar na figura que, na faixa etária de 4 a 10 meses, predomina o estado de irritação momentos antes da retèição e que, com o aumento da idade, há um decréscimo na manifestação desse estado de humor. De 11 a 18 meses, pouco mais da metade dos bebês femininos mostra-se calma enquanto aguarda a papa salgada, os demais permanecem irritados. A maioria dos bebês de 19 a 24 meses está calma antes da refeição e depois dela predomina, em todas as faixas etárias, a calma e a tranqüilidade. Não foi relatada a presença de bebês desse gênero julgados como Alegres/Felizes antes ou depois da papa salgada.

As observações no Diário de Campo mostram que após a alimentação o clima geral nos berçários é de tranqüilidade, rompida apenas por um ou outro bebê que resmunga ou choraminga.

\section{O Sono}

Bebês de 4 a 6 meses de idade dormem em diferentes lugares e há uma variação em função do sexo: predomina para os masculinos o carrinho/berço e para os femininos o berço/quadrado. As educadoras comentam que preferem que os bebês durmam nos berços ou quadrados porque julgam mais confortáveis:

"Às vezes ela dorme no carrinho aí ela é colocada no berço, por causa da posição, cansa se ficar no carrinho, no berço fica mais acomodada ".

Cem por cento dos bebês de 9 a 22 meses, de ambos os sexos, dormem nos quadrados e os de 23 e 24 meses nos colchonetes.

\section{Outras exigências dos bebês}

Outro aspecto observado foi a presença da chupeta, "paninhos" ou mesmo a variedade de posições em que os bebês são colocados para dormir. Quando as ducadoras foram indagadas, elas descreveram as preferências e as acomodações dos bebês.

Para bebês de 4 a 6 meses de idade sobressai a exigência da posição de bruços e a necessidade de fralda e chupeta. Na faixa etária seguinte aparece certa diferença em função do sexo, mas o que sobressai ainda é o mesmo: a posição de bruços para dormir. Nessa idade, os bebês masculinos recorrem menos à fralda e à chupeta que os femininos, mas ainda assim são esses os comportamentos predominantes. Aparece também, nessa faixa etária, um aumento do percentual do comportamento de chupar o próprio dedo, para ambos os sexos.

De 20 a 24 meses, as diferenças em função do sexo são grandes, em todos os comportamentos relatados: mais bebês masculinos chupam chupeta, enquanto os femininos necessitam da posição de bruços, da fralda e da chupeta.

Há um percentual constante de bebês do sexo masculino em diferentes faixas etárias (14\%) que não apresentam necessidades específicas nessa situação, o que não ocorre com os femininos.

Segundo as educadoras, o comportamento dos bebês na hora em que vão dormir manifestase de seis maneiras: (a) brincam; (b) sentam/levantam-se; (c) emitem sons, falam, cantam; (d) mantêm-se quietos; (e) choram; (f) resmungam/ inquietam-se. Esses comportamentos foram agrupados em três categorias. "Entretêm-se" quando o bebê brinca, emite sons/ fala/canta, senta ou levanta-se. "Mantém-se quieto" quando ele permanece quieto, observando o ambiente. "Desassossega-se” quando chora, resmunga, inquieta-se ou senta/levantase, associado ao choro e ao resmungo. Na Figura 5 pode-se observar esses dados em função do sexo e faixa etária dos bebês.

Na faixa etária de 4 a 10 meses predominam comportamentos que indicam desassossego para ambos os sexos, embora em proporção maior para o feminino. De 11 a 18 meses aumenta a porcentagem dos bebês masculinos que se mantêm quietos nessa hora, mais do que para os femininos, que têm a mesma proporção de desassossego. Na faixa etária seguinte a maioria das meninas permanece quieta. Por outro lado, embora pouco mais da metade dos meninos mantenha-se quieta, os demais se entretêm brincando, emitindo sons, e mudando de posição. 

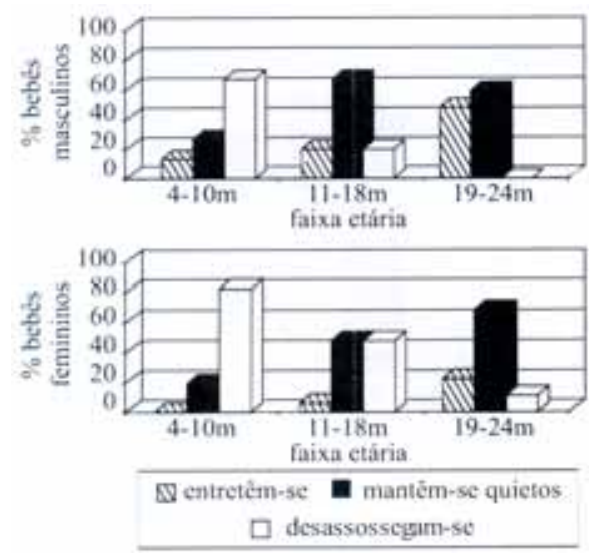

Figura 5: Proporção de comportamentos de bebês na hora em que são colocados para dormir, em função do sexo e da faixa etária

\section{A qualidade do sono dos bebês}

Analisando a qualidade do sono dos bebês, o relato das educadoras permitiu classificálo em duas dimensões: agitado e calmo. A maioria dos bebês de ambos os sexos apresenta sono calmo (em torno de 98\%).

Analisada a quantidade de sono dos bebês, o julgamento das educadoras o coloca, mais freqüentemente, na categoria "normal".

Passado o periodo de sono, as educadoras descreveram como é “o acordar” dos bebês. Elas relataram a ocorrência de sete comportamentos: (a) brincam; (b) riem; (c) emitem sons/falam/cantam; (d) sentam/levantam-se/caminham; (d) mantêm-se quietos observando o ambiente; (e) choram; (f) resmungam/inquietam-se.

Na Figura 6 encontram-se os comportamentos descritas acima agrupados em três categorias: "Entretém-se" quando o bebê brinca,
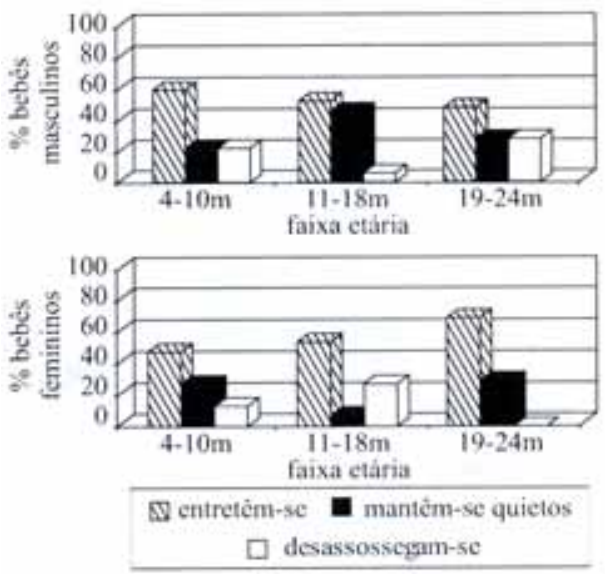

Figura 6: Proporção de categorias de comportamentos de bebês ao acordarem em função do sexo e da faixa etária domina o estado de Calma/Tranqüilidade. Quando mais velhos, com 19 a 24 meses, estão calmos antes de dormir, e o bom humor permanece depois.

\section{A Situação de Higiene}

\section{A troca de fraldas}

A troca de fraldas ocorria com certa periodicidade, geralmente antes e depois de cada refeição e sempre que percebiam a necessidade. Oitenta e oito por cento dos bebês do sexo feminino aceita bem a troca de fraldas, $5 \%$ manifestam desagrado nessa hora e 7\% não usam mais fralda (três dentre os mais velhos) tendo adquirido controle da bexiga sem nenhum treino por parte das educadoras. Entre os bebês do sexo masculino, 93\% aceita bem essa situação e o restante manifesta irritação.

As educadoras relataram que os bebês, quando trocados, emitem sete classes de comportamentos: (a) riem ou sorriem; (b) tentam pegar objetos próximos (fita crepe, calça plástica, fralda); (c) emitem sons: repetem sílabas ou dizem palavras ou frases; (d) agitam o corpo, batem as pernas; (e) tentam sentar, quando deitados; (f) mantêm-se quietos, observando o ambiente; (g) choram. Alguns bebês emitem mais de um desses comportamentos nessa situação.

Na Figura 9 encontram-se os comportamentos descritos acima agrupados em três categorias: "Entretêm-se" quando riem ou sorriem, tentam pegar objetos próximos, emitem sons; "Mantêm-se quietos" quando observam o ambiente sem emitirem outro comportamento; "Desassossegam-se" quando choram, agitam o corpo, batem as pernas ou tentam sentar quando deitados.
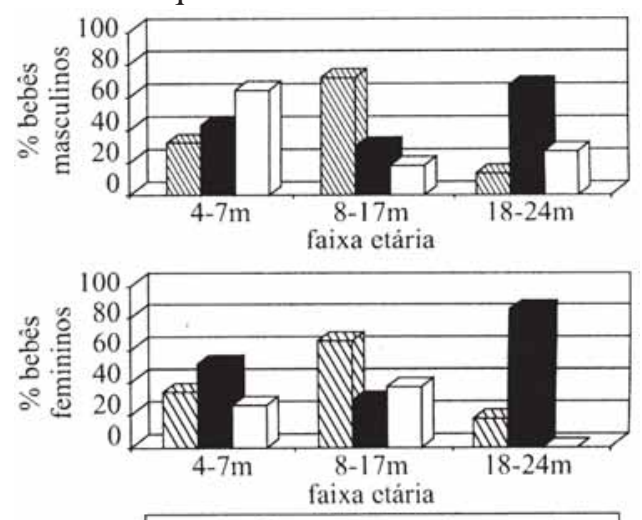

ष్ entretêm-se $\mathbf{n}$ mantêm-se quietos

$\square$ desassossegam-se

Figura 9. Proporção de comportamentos de bebês em relação à maneira que costumam agir durante a troca de fraldas, em função do sexo e da faixa etária 
Na faixa etária de 4 a 7 meses predomina a categoria "desassossegar-se" para bebês do sexo masculino e o "manter-se quieto" para os femininos. Na faixa etária de 8 a 17 meses, mais da metade dos bebês, de ambos os sexos, "entretêmse”, durante a troca de fraldas, tentando pegar ou pegando objetos. De 18 a 24 meses, a maioria dos bebes do sexo feminino mantém-se quieta e os masculinos agem de forma semelhante, embora em menor proporção. Um quarto dos bebês masculinos mostra-se desassossegado, chorando nessa situação.

\section{O humor na situação de troca de fraldas}

A Figura 10 apresenta as porcentagens de bebês de ambos os sexos e o humor que manifestam na troca de fraldas, em função da faixa etária.

Fica evidenciado na figura padrões bem semelhantes para a faixa etária de 4 a 10 meses, em função do sexo, tendo maior destaque a calma/tranqüilidade, seguida de alegria/felicidade. Nas idades seguintes, a maioria dos bebês mostra-se calma/tranqüila.
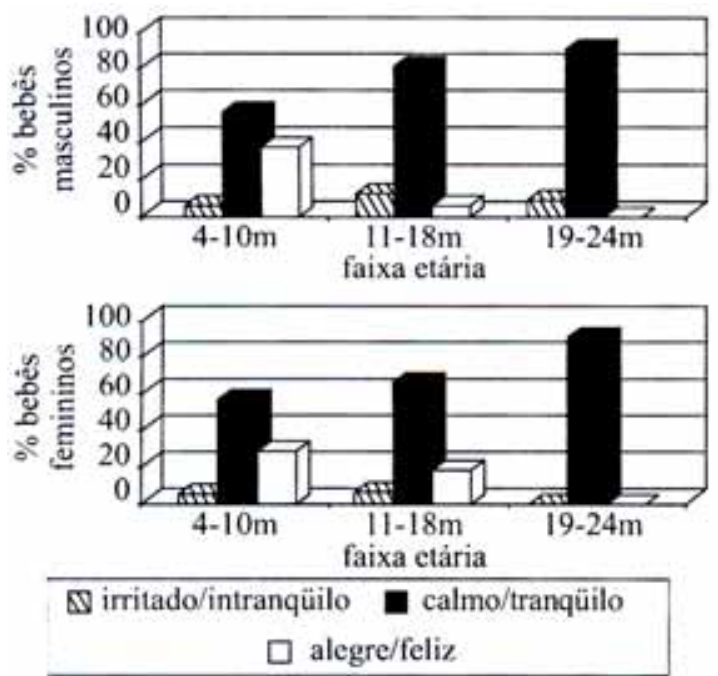

Figura 10: Proporção de categorias de humor apresentado pelos bebês durante a troca de fraldas, em função do sexo e da faixa etária

\section{O Banho}

Cada bebê era banhado individualmente por uma educadora, geralmente uma vez ao dia, no período da manhã ou da tarde.

Segundo o relato das educadoras, $95 \%$ dos bebês tomam banho na creche e nessa situação apresentam 11 classes de comportamentos: (a) brincam com a água, tentam pegá-la; (b) riem ou sorriem; (c) tentam pegar objetos (sabonete, saboneteira, fita crepe) ou conseguem pegá-los; (d) emitem sons, repetem sílabas ou dizem palavras ou frases; (e) ficam mexendo ou impulsionando as pernas; (f) tentam alterar a posição esticando as pernas quando sentados ou agachados dentro da cuba do banho; (g) atendem as solicitações da educadora levantando os braços, pernas, fechando os olhos; (h) mantêm-se quietos, deixando-se manipular pela educadora, (i) choram no início do banho ou ao lavarem a cabeça; (j) choram durante todo o banho; (k) ficam resmungando, expressando desagrado.

Como pode ser verificado, há grande diversidade de comportamentos e o comum é a emissão de vários deles durante o banho. A Figura 11 apresenta esses dados agrupados em quatro categorias: "Entretêm-se" quando tentam pegar/ pegam/objetos, brincam com a água, riem, emitem sons; "Colaboram com a Educadora" quando atendem suas solicitações; "Mantêm-se quietos" quando ficam observando o ambiente, sem emitirem outro comporlainento e "Desassossegam-se" quando choram no início ou durante todo o banho, resmungam, tentam alterar a posição do corpo, mexem, impulsionam as pernas.

De 4 a 7 meses sobressai, para bebés de ambos os sexos, duas categorias: entreter-se e desassossegar-se, embora em menor proporção para os femininos. Nos bebés de 8 a 18 meses predomina a categoria entreter-se: eles tentam pegar ou pegam objetos, brincam com a água, riem e emitem sons. Na faixa etária seguinte, a categoria mais aparente e que não havia antes, é o de colaborar com a educadora atendendo às suas solicitações. Outro comportamento a ser destacado para os bebés femininos é o entreter-se.

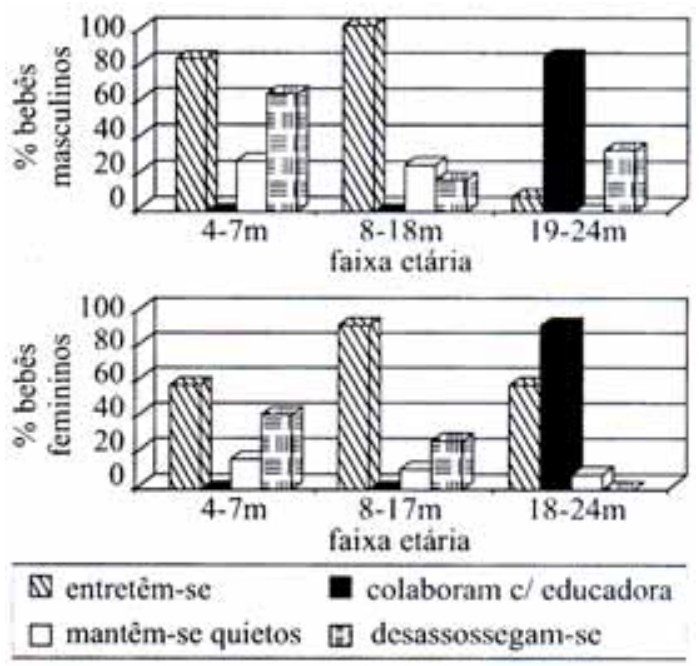

Figura 11: Proporção de categorias de comportamentos que bebês, de ambos os sexos e diferentes faixas etárias emitem durante o banho 
Dados observacionais indicam que as educadoras, durante a hora do banho, têm preocupações fundamentalmente higiênicas. Há uma seqüência mais ou menos fixa em que os bebês são banhados, iniciando-se por lavar a cabeça, o rosto, pescoço. A duração do banho, incluíndo o despir, o vestir e pentear o cabelo é de 4 a 6 minutos. Elas se preocupam em executar a tarefa de forma cuidadosa, mas controlam os movimentos do bebê que atrapalham o banho tais como: pegar objetos, tentar levantar-se, movimentar muito as pernas. Nessa situação não há brinquedos por perto e os objetos disponíveis são os utilizados pela educadora, como saboneteira e fita crepe.

\section{O humor do bebê na hora do banho}

A Figura 12 apresenta os dados de como fica o humor dos bebês durante o período em que estão tomando banho.

De 4 a 10 meses predomina, para bebês masculinos, amanifestação de Alegria/Felicidade; já o humor dos bebês femininos apresenta-se menos concentrado em uma categoria específica, apesar de sobressair a alegria.
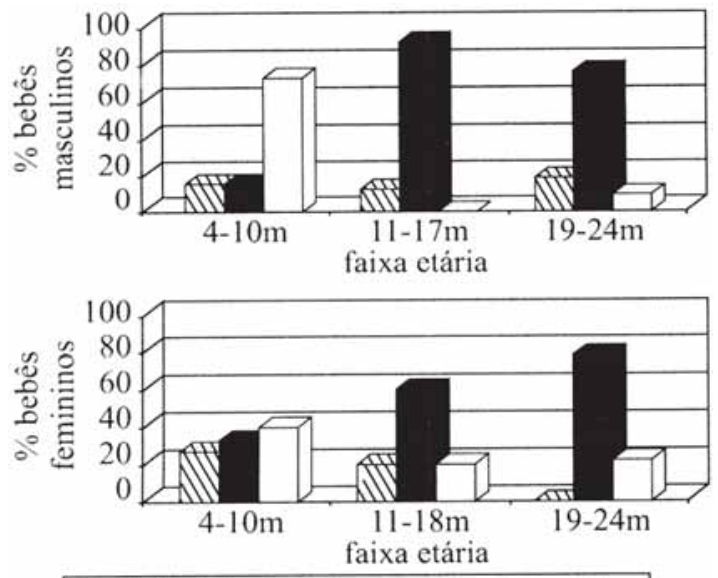

$\mathbb{\nabla}$ irritado/tranqüilo $\mathbf{c a l m o / t r a n q u ̈ i l o ~}$ $\square$ alegre/feliz

Figura 12: Proporção de categorias de humor apresentadas pelos bebês durante o período em que são banhados, em função do sexo e da faixa etária

Nas faixas etárias seguintes, há grande alteração no padrão de humor apresentado: a maior parte dos bebês de ambos os sexos mostra-se calma/tranqüila.

Destacando o estado de irritação, observase que ele aumenta para os meninos e diminui para as meninas, com o passar da idade e a alegria/felicidade diminui para ambos os sexos.
Os dados do Diário de Campo permitem acrescentar que as educadoras geralmente conversam com os bebês nessa hora e demonstram carinho através de beijos e abraços. Os bebês permanecem calmos durante essa atividade.

\section{Atividade Livre}

As educadoras relataram onde os bebês costumam ficar, no período considerado como de Atividade Livre. Na faixa etária de 4 a 8 meses eles são colocados em locais variados: no berço/quadrado, carrinho de bebê e colchonete ou chão do berçário e que todos bebês femininos ficam nos carrinhos, o que não ocorre com os masculinos. Ao relatar porque não colocavam alguns bebês no carrinho houve frases como: "Ele é bem esperto. É uma criança que já levanta no carrinho. você não pode deixar no carrinho sem roce tá perto se não ele levanta, se não ele levanta e cai mesmo".

Bebes de 9 a 17 meses, de ambos os sexos, são colocados no chão, no quadrado e levados para o pátio e/ou parque. Na faixa etária de 18 a 24 meses predomina espaços abertos como o chão do berçario, o pátio e o parque.

As educadoras também relataram que todos os bebês, de todas as faixas etárias descritas, observam estímulos do ambiente. A maioria entretêm-se com brinquedos, mas 10\% dos femininos (três bebês de 4 ou 5 meses e um de um ano) e $2 \%$ dos masculinos (6 meses) não o fazem. Esse padrão está presente desde os 4 meses de idade para bebês de ambos os sexos.

Verificou-se também se os bebês preferem entreter-se com brinquedo de forma mais isolada, perto dos outros ou em interação. Cerca de $80 \%$ dos bebês masculinos de 4 a 8 meses brinca só e perto de outros; para os femininos predomina o brincar só (80\%). Já de 9 a 17 meses, sobressai o brincar com o(s) outro(s) para ambos os sexos (cerca de $43 \%$ ), no entanto $40 \%$ dos bebes femininos ainda preferem ficar só. De 18 a 24 meses iguala-se o tipo de prelèrência dos bebês de ambos os sexos: brincar interativamente.

As observações mostraram a presença de brinquedos variados: musicais, chocalhos, bichos de borracha, blocos, brinquedos de montar, bonecas, quebra-cabeças, entre outros. Há também livros infantis para os maiores. As paredes dos berçaários e da sala contíguas onde os bebês são banhados e trocados, são enfeitadas com desenhos e móbiles.

\section{DISCUSSÃO}

Os dados mostram como bebês de 4 a 24 meses se comportam nas atividades rotineiras do CCI, em função do sexo e da faixa etária. De modo 
geral, eles acham-se adaptados à situação coletiva: apreciam o banho de sol; alimentam-se bem e passam a esperar pela papa salgada com mais tranqüilidade, brincando e se locomovendo no berçário, o sono é calmo e considerado numa quantidade normal; demonstram aceitação na troca de fraldas e no banho; permanecem em espaços amplos nas atividades livres e, com o aumento da idade, apresentam maior participação nas atividades interativas com outros bebês. No entanto, alguns aspectos merecem ser destacados.

A faixa etária intennediária dos 8 aos 12 meses, aproximadamente, parece ser um período de transição entre os comportamentos apresentados pelos bebês mais novos e pelos mais velhos, ocorrendo uma inversão nos comportamentos da primeira faixa para a terceira. Em relação à alimentação, ocorre uma alteração na quantidade de alimentos ingeridos por parte dos bebês dessa idade: menos da metade dos bebês ingere uma quantidade vista como normal, aumentando o percentual dos que comem pouco ou de forma exagerada. Outro aspecto a ser salientado, para ambos os sexos, é a diminuição da manifestação de alegria na situação de troca de fraldas e de banho pelos bebês de 11 a 24 meses. Isso parece ocorrer em função das educadoras atribuírem a essa atividade função primordialmente higiênica, visando a promoção de bem estar e saúde. A esse respeito, GUIMARÃES (1998), MEEEO e VITORIA (1998) destacam a importância do banho na interação do bebê com a educadora e, quando acima de 7 meses, com outros bebês também, em situação coletiva, propiciando o brincar, o aprender e a construção de bons hábitos.

Em relação à diferença entre os dois sexos, bebês masculinos são descritos como mais agitados dos 4 aos 8 meses, por isso alguns não podem ser colocados nos carrinhos e são mais interativos ou sociáveis dos 9 aos 17 meses. Dos 19 aos 24 meses há maior número que manifesta irritação depois que acorda, o que não ocorre com os femininos.

Um outro aspecto a ser destacado e que aparece praticamente em todas as situações rotineiras da creche é o comportamento dos bebês femininos mais velhos em contraposição aos masculinos. Antes da papa salgada, há mais bebês masculinos, de 19 a 24 meses, que manifestam irritação do que os femininos. A totalidade das meninas, de 19 a 24 meses, mostra-se calma quando vai donnir; dentre os meninos alguns estão irritados. Ao acordar, aproximadamente um quarto dos bebês masculinos de 19 a 24 meses mostra-se desassossegado, com quase 30\% manifestando irritação, enquanto os femininos entretêm-se com brinquedos, se locomovem, mostrando calma e alegria. Na situação de troca de fraldas, quase um quarto dos meninos mostra-se desassossegado, o que não ocorre com as meninas. Na situação de banho há a mesma coisa: um percentual de bebês masculinos está desassossegado, irntado e os femininos acham-se calmos e alegres.

Esses dados sugerem algumas perguntas. $\mathrm{O}$ que faz com que bebês femininos, de idade em torno de 18 a 24 meses, mostrem-se mais tranqüilos, conformados, aceitando as situaçoes? Há diferenças no temperamento? As educadoras tratam os bebês de forma diferente em função do sexo? Esses dados são específicos dessa creche em particular? São similares a de outros contextos coletivos? E nos bebês que permanecem em seus lares, será que essa diferença se mantém?

Os dados obtidos nesse estudo geram perguntas, mas não fornecem respostas. Há portanto, a necessidade de novas pesquisas.

\begin{abstract}
This work aimed to check how babies behave in the daily routine of a day nursery located in the countryside of the state of Sao Paulo. The information was obtained through semistructured interviews with 2 I day nursery educators who were individually interviewed about each baby from 4 to 24 months of age under their care $(n=90)$, and also through the field diary, used as a strategy for gathering complementary information. The data were analysed in a quantitative, quantitative-interpretative and qualitative manner. The results of the study indicate that this sample of babies is adapted to the collective environment: they enjoy the sun bath, eat well and wait for their food calmly playing and rnoving around in the nursery; their sleep is calm and in a normal quantity; they show acceptance in the changing of nappies and in the bath; with the increase of age they show greater interest in the interactive activities with other babies. However, some aspects are outlined and it is acknowledged that there is the need of new research to clarify them.
\end{abstract}

Key words: babies; behaviour; day nursery. 


\section{REFERÊNCIAS BIBLIOGRÁFICAS}

CALDWELL, B. Creche, - bebê, família e educação. In: GOMES, J. P. Bebê XXI. Criança e família na viragem do século. Lisboa: Fundação Calouste Gulbenkian, 1995. p. 465-48

GUIMARÃES, L. Banho: Que delícia! In: ROSSETTI FERREIRA, M. C.; MELLO, A. M.; VITÓRIA, T.; GOSUEN, A.; CHACURI, A. C. Os fazeres na educação infantil. São Paulo: Cortez, 1998. p. 115.
MELLO, A. M.; VITORIA, T. Bolhinhas de sabão... o banho das crianças na creche. In: ROSSETTI FERREIRA, M. C.; MELLO, A. M.; VITÓRIA, T.; GOSUEN, A.; CHACURI, A. C. Os fazeres na educação infantil. São Paulo: Cortez, 1998. p.116- 119.

SIGOLO, S. R. R. L.; BIASOLI-ALVES, Z. M. M. Análise de dados de interação mãe-criança: Construção de sistemas de categorias. In: ROMANELLI, G.; BIASOLI-ALVES, Z. M. M. Diálogos metodológicos sobre prática de pesquisa. Ribeirão Preto: Legis Summa, 1998. p. 87-118. 